\title{
Utilizing Balabolka to Enhance Teaching Listening
}

\author{
Mike Amelia \\ Faculty of Teacher Training and Education \\ Mahaputra Muhammad Yamin University \\ Solok, Indonesia \\ ameliamike@yahoo.co.id
}

\begin{abstract}
Many Studies in language learning have indicated that listening becomes one of neglected literacy skill in learning English. This happen because it is the most difficult skill to teach. The purpose of the present article is to define the use of Balabolka as a current media which could help teacher in teaching listening in the classroom. Balabolka is one of an application that can be downloaded from internet, this program uses various versions of Microsoft Speech API (SAPI), it allows to alter voice's parameters including rate an pitch. The user can apply special substitution list to improve the quality of the voice's articulation. When an audio file is played with players on a computer or on modern digital audio players, the text is displayed synchronously (at the same way, as lyrics for songs). By utilizing this media, it can facilitate teachers to be creative in designing their teaching listening materials.
\end{abstract}

Keywords—utilizing; balabolka; listening

\section{INTRODUCTION}

Listening activity plays important roles in daily life comparing with another skills. People do Listening more than Reading, Speaking, and Writing, many adults used $45 \%$ of their time to Listen, $30 \%$ to speak, $16 \%$ to read and only $9 \%$ to write [7]. The importance of listening skill is also seen at school especially in learning English. Students use most of their time to listen what the teacher said. Many experts say that the success of the students in understanding the lesson is started from students' ability in listening. Based on the facts above, listening skill is needed to be mastered by the students.

However, there are many evidences show that listening is lack attention of teachers [1] when teacher applied many learning competencies in the classroom, listening skill is always accelerated or reduced. Teaching course methodology was discussed and analyzed slightly, and there was a tendency from teachers that listening was ordinary activity in life. The other factor is lack of teacher's commitment to apply an appropriate approach in listening like using integrative skill which affected listening as an indicator to teach it in haste. In addition, some technical problems on teaching facilities, difficulties in finding the materials and problems on designing their own materials due to limitation in quality of pronouncing materials are also become the sources of obstacles in teaching listening.
Since internet have been one of the source of teaching tools which can help teacher in many aspects, there is no reason for English teacher not to consider listening skill. With the advanced technology, integration of materials in language classroom has become wide spread [10]. The need to find a good way to exploit materials to their full potential has been urgently felt. In recent year, teaching listening has been developed and advanced especially in media and in teaching materials used with well equipped language laboratories and classrooms, it is increasingly hard to find an audio only listening presentation.

Besides, instant materials, songs, features movies, talk shows and so fourth have become a daily part of peoples' life and more off- air authentic visual recording have found their way into language classrooms. In this case, Balabolka seems to give an answer in the process of preparing media for teaching listening. The arising of the listening media using Balabolka starts from the consideration where the teacher should provide a media which is feasible and economical to create individually by the teachers themselves in teaching listening.

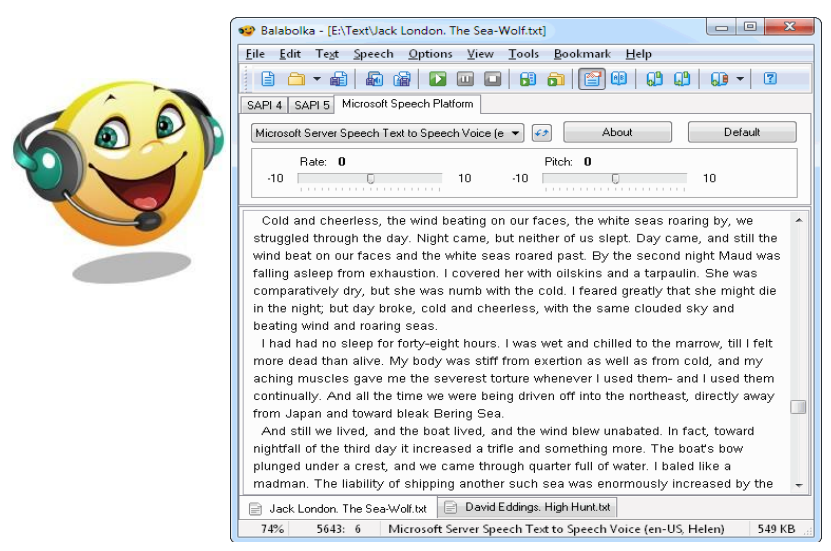

\section{Balabolka software}

Balabolka is application that is used in all activities based on free software Text to Speech in computer system. Balabolka is meaningful to improve languange skill, especially in listening skill. People can set sounds, intonation, 
pitch, strees and others based on willing of people itself. The importance thing in Balabolka is people can produce sounds or audio from reading aloud that people made in the application. The on- screen text can be saved as a WAV, MP3, MP4, OGG or WMA file. The program can read the clipboard content, view the text from AZW, CHM, DjVu,DOC,EPUB, FB2,HTML, LIT,MOBI, ODT, PRC, PDF and RTF files, customize font and background color, control reading from the system tray or by the global hotkey. The program uses various versions of Microsoft Speech API (SAPI); it allows altering a voice's parameters, including rate and pitch. The user can apply special substitution list to improve the quality of the voice's articulation. This features is useful when changing the spelling of words. The rules for the pronounciation correction use the syntax of regular expressions. Balabolka can save the synchronized text in external LRC files or in MP3 tags in the audio files. When an audio file is played with players on a computer or with modern digital audio players, the text is displayed synchronously (at the same way, as lyrics for songs).

Balabolka is a marvelous free software the program computer [5]. It can be called like that because Balabolka can change text become sounds or rics voices in the language. Then, Balabolka has kinds of features, not only to reading aloud but also as a translator in the program. The users can choose it as a TTS (Text to Speech) for all competences. In addition, Balabolka is derived from a Russian word, it means that a chatter in Russian. In Balabolka, digital text files can be obtained by TTS program in windows computer [8]. Thus, the result of digital text file is audio files that can be produced and replay with other tools like MP3 players, MP4 and the others.

Furthermore, the clipboard content can be read by using a free TTS device in Balabolka [8]. Many voices in storage system can be used based on necessary. It means that, people can use Balabolka according to their needs and aspects. Then, people can set and manage the content of reading. It is useful for people to enrich and expand vocabulary in the content. Thus, language education can use this application to drill their skill. It will drill their skill, because Balabolka can set the speed and pitch that helps them in their listening skill.

The teacher can apply a special substitution list to improve the quality of the voice's articulation. This feature is useful when we want to change the spelling of words or separating syllables. Balabolka uses two kinds of substitution lists: 1) the rules for the pronounciation correction use the syntax of regular expressions and can be saved in the files with the extension *.rex; 2) files with the extension *.dic; .The syntax of rules is simple, so the file can contain thousands of rules. Files for pronounciation correction are saved in the folder My Documents/ Balabolka (or Documents/ Balabolka in Windows Vista and Window 7). If any dictionary used, the program highlights the whole sentence or paragraph during reading : otherwise : the current word is highlighted.

Balabolka has many fetures. Where to start? (Kennedy; 2009 ) list the significant features of balabolka: a. Download a full version to an MS Windows computer (ex; WIN 2000, 2003, and Vista), or download portable version (it can add to access Apps! Teach Apps or LearnApps USB drive). It is all about 2,4 MB in size.

b. It will access SAPI 4 and 5 voices on MS Windows Computer

c. It runs in full screen mode or in a window

d. It has a pronouciation editor built in

e. It offers a spell checker ( with options and some exceptions)

f. A built in magnifier is a available

g. It will convert text to audio

h. It can change the background, text and highlight colours

i. It can change the font size and style

j. Rate pitch and volume of the voice are easily altered with slide bar controllers

k. The interface intuitive with easy to access icons an d toolbar

1. It is so customisable

m. You can start speech then pause or stop it ad also read the clipboard (all with associated function)

n. There are numerous short- cut equivalents!

o. Text can be saved as either a text file or as an audio file ( with or without ID3 tags).

p. Users can insert and set bookmarks!

q. It even has five skins (i.e change the look and feel and colour scheme...)

r. Thirteen languges are provided (ideal for LOTE students)

\section{Program Option}

Balabolka offers many different options for configuring the program interface and the different aspects of handling digital text files and converting them into digital audio files.

\section{a. Pronounciation Correction}

Balabolka provides the user with the ability to create multiple pronounciation profiles and the ability to search for different instances of words and rules alike.

b. TTS Options

Control the speed, pitch, and volume of the audio generated by Balabolka. Users can also reset the audio setting to the default values.

c. Audio Files

Users can configure the details of the recorded audio file made by Balabolka through the Audio Files setting dialog.

\section{Setting Option}

Balabolka features a rich setting panel under the options menu. There are twelve tabs in the setting panel, which allows the user to configure and control all of the 
critical aspects of running Balabolka. The different tabs of the setting panel are labeled:

a. General - allows you to select the options of where reading should begin (Cursor, beginning of text, beginning of paragraph), as well as where the recording should begin. Behavour for how the program should operate upon start up and while minimized, as well as text echo parameters are controlled in General tab.

b. Reading - provides options to configure reading behaviour at line breaks and end of file, configure compatability with screen reading applications, the ability to track spoken text,and how to track the spoken text ( centered or fit to limits of window).

c. View - configures the look of the interface and controlls what sort of data is presented. Selections to show the status bar and what to include in the status bar are found here.

d. Pauses - allows the users to configure the length of pauses during reading and recording audio tracks.

e. Text - the users can control whether the text will be formatted automatically or not. Allows for the the automated clean up of text files, such as removing double line breaks, hyphens et end of lines, and line breaks within paragraphs.

f. Hotkeys - allow the user to configure the primacy reading controls and o determine if they are active or not.

g. Shortcuts - in the shortcuts tab you can create or change keyboard commands for any of the menu functions in Bolabolka.

h. Buttons - user can determine which buttons to have visible on the icon- based menu bar, and change their position and grouping on the menu bar.

i. Files - allows the user to configure which application to use when importing text files.

j. Rules - the rules tab features pronounciation settings to control how Bolabolka will present the audio phrasing of the text it reads. The settings can be changed from sentences to paragraphs or a combination there of in order to deliver a more natural - sounding delivery of the spoken words.

k. LRC - Balabolka can also generate an LRC file for use in other digital audio players. The LRC file contains the digital text and timing information, so that the visual text can be presented at the same time as the spoken audio of the text.

1. Voice - the voice tab allows the user to select between SAPI 4 or SAPI 5 or to use the voice settings from the last documents.

Under the option menu. Balabolka also provides options for configuring the rate pitch and speed of the voice as well as spell checking and timers for turning the program of after it finishes generating audio files.
Tools

Balabolka also features several tools that enable the user to perform powerful operation on their digital text files

File Splitter

Balabolka will split one long file into smaller files.

Batch File Converter

Balabolka will convert multiple files into audio files.

Extractc Text from files

Balabolka will load selected files and extract the text into a directory specified by the user.

Compare Two files

- Present in both files

- $\quad$ Present in one of the files only

- $\quad$ Present in second file and absent in firstly file

- Present in files (sum of files)

- Enrich the reading and educational experience of the user.

\section{Repeat text}

Repeat text will allow a user to specify text that can be repeated throughout the document as a memory aid or as attempted remediation of memory and recall issues.

Based on the explanation of the expert above, it can be concluded that Balabolka is a freeware application that is derived from TTS (Text to Speech) and it based on windows system operation. Balabolka is a creative application that make and change text to sounds although using different accent and language. Then, it can also used in environment of education, because it helps students to improve English skill especially in listening skill.

\section{DISCUSSION}

There are some ways to operate and use Balabolka such as opening file, saving file, splitting audio file, and playing file [8]. Meanwhile, there are several procedures on using Balabolka to improve listening as soon as reading [6]. First, take the text and click "Copy" and "Paste" in Balabolka. If there are sources in documents, it could be copied into main content window of Balabolka. Next, people can choose icon "Read Aloud" in Toolbar, Balabolka will read and set of rate, pitch and volume on the text. Finally, it can be saved although having various form of audio format, it can be done by clicking "File" and "Save" the audio file.

Moreover, there are several steps on how to use Balabolka which is useful and helpful for beginner, the step is clicking "File" and choose file then click "Open" [11]. After that, appearance of text on balabolka can be changed in order to be more interesting. Then, to change the font or Color just click on Menu "View" in Toolbar. It means that, not only there is setting of articulation for the user, but also Balabolka is having ways to set appearance of text. There are some procedures of how to operate Balabolka. First, to have a new document is by clicking Menu "File" in toolbar above and click "Open" to create and using Balabolka. Then, if the document is already finish, it can be saved by click Menu 
"File" and click "Save" to saving the document. Last, there is also way to convert video file to be audio file, it can be done by click "File" and then click "Split and Conver to Audio File Convert to Audio File". It means that, there is an instruction on how to operate Balabolka [3].

Balabolka is also apart of interesting media that can be used in classroom in teaching listening. There are some steps of teaching listening by using Balabolka: First, Find the topic which may be interesting for students. This can be related to the topic which has been covered in the class by a teacher. The topic can be covered in the class by the teacher. The topic can be in form of conversation or text. Second, the teacher asks the student to get a pair to practice their listening comprehension by utilizing Balabolka. Each pair should find out about their partner interest in academic life or their hobbies. This activity is aimed at giving students opportunity to choose topics available on Balabolka. However, teacher as facilitator has to define general topic like social media, fashion, sport or other general term. Beside, length and difficulty level do need to be set by the teacher to ease the students understand on the topic. Third, By explanation and guidance from the teacher about how to use Balabolka each student in pair search for a a topic that has been prepared by the teacher. Fourth, Student listen to the Balabolka choosen while taking a note about the content from which to construct the meaning. Fifth, teacher briefly check students' question and key prior to the lesson in which they will change the Balabolka and tasks with their partner. Sixth, After checking the students' question the teacher may give a feed back in order to keep students' motivation. The last, have the students to swap their balabolka and tasks in pair.

In conclusion, utilizing Balabolka could facilitate teacher especially in designing listening materials by themselves. Teacher could create their own assesment based on the students' level and students' need. The teacher do not need to consider how to produce the source of voice native speaker, the full speech at difference paces, different intonation and different level of correctness and the good pronounciation. On the other hand, this media is an effective media that can be used in every situation. It is not becomes a big problem whether there is no laboratory at school, because this media can be operated without laboratory facility.

\section{CONCLUSION}

As one of multimedia technology, Balabolka becomes more accessible to teachers and learners of other languages, its potential as a tool to enhance listening skills becomes a practical option. Balabolka allows integration of text, audio in a range of combinations. The use of Balabolka can help teacher in creating their own material in teaching listening. By using Balabolka the teacher can create and convert text files into audio files in MP3 and other format. If the original text has been structured properly, Balabolka can be set up to automatically create a new file. The result is that learners can interact with textual, aural, and audio media in a wide range of formats. Consequently, when computer is used as potentially supporting listening skills acquisition, the thing which is needed to examine not only aural processing opportunities, but also in simultaneous sight, sound, text processing as well. This media is an interactive media which can help teacher in teaching listening.

\section{References}

[1] Field, J. Listening in the Language Classroom. Cambridge: Cambridge University Press. 2009

[2] Flowerdew, J. And Lindsay M. Second Language Listening. Cambridge: Cambridge university press. 2005

[3] Herawati, Yayuk Widyastuti. "Integrating Character Education and Local Genius through Balabolka in Teaching Listening”. LINGUA, 11(1). Retrieved on http://repository.uin-malang.ac.id/618/. On January, $13^{\text {th }} 2017.2016$

[4] Ivers, K.S.,and Baron, A.E. Multimedia Projects in Education. (Second Edition) Englewood,co: Libraries Unlimited. 2002

[5] Kennedy, Gery. "Review of Balabolka: Gerry Kennedy IT Consultancy. English Grammar. New York: Oxford University Press. 2009

[6] Muna, Faizul. "The Use of Pronounciation Software to Improve Students' Pronounciation Encounter". Vol. 3(2). 2012 Retrieved on http://id.portalgaruda.org/?ref=browse \&mod=viewarticle $\&$ article=15414 9. On January, $13^{\text {th }} 2017$

[7] Rivers, W. M. Teaching foreign-language skills (2nded.). Chicago: The University of Chicago press. 1997

[8] Road, McClellan. Creating Accessible PDFs: High Tech Center Training Unit. California: California Community Colleges. 2011

[9] Road, McClellan. 2011. Alternate Media for E-Book Readers: High Tech Center Training Unit. California: California Community Colleges. 2011

[10] Vanderplank, R. "Deja vu? A decade of research on language laboratories, television and Video in Language Learning," in Language Teaching, 43,1:1-37. 2010

[11] Wilson. J. D. 2014. How to teach listening. Harlow: Pearson Longman. 2014 